\title{
PEMANFAATAN TEKNOLOGI KOMPUTER SEBAGAI MEDIA PEMBELAJARAN PADA GURU MATEMATIKA
}

\author{
Moh Zayyadi ${ }^{1^{*}}$, Lili Supardi ${ }^{2}$, Septiyadini Misriyana ${ }^{3}$ \\ ${ }^{1}$ Program Studi Pendidikan Matematika, FKIP, Universitas Madura \\ Alamat Jalan Raya Panglegur 3,5 KM Pamekasan \\ e-mail: zayyadi@unira.ac.id
}

\begin{abstract}
ABSTRAK
Di daerah Tlanakan Pamekasan banyak para guru MTs yang hanya menggunakan media secara manual saja dalam pembelajaran yang dilakukannya. Ada beberapa alasan, diantaranya, kurangnya pengetahuan mereka dalam penggunaan aplikasi komputer untuk menciptakan suatu media yang berbasis teknologi. Solusi yang dapat diberikan untuk permasalahan yang dialami oleh guru matematika tersebut adalah dengan memberikan pelatihan dengan memanfaatkan aplikasi/program komputer sebagai media/alat pembelajaran. Aplikasi tersebut berupa software geogebra dan maple yang nantinya bisa diterapkan oleh para guru. software seperti ini sudah banyak diaplikasikan sebagai alat pembelajaran di berbagai sekolah negeri. Target yang ingin dapat meningkatkan pemahaman guru tentang peranan media pembelajaran pada umumnya dalam pembelajaran matematika, khususnya yang berbasis teknologi dan meningkatkan keterampilan guru dalam menggunakan Geogebra dan Maple untuk membuat media pembelajaran matematika virtual. Hasil temuan dalam kegiatan ini adalah Kegiatan pengabdian mendapatkan respon positif dari guru-guru matematika SMP/MTs dikarenakan dapat membantu guru-guru dalam mengerjakan soal matematika dan Kegiatan pengabdian ini berbentuk teori dengan memberikan modul pada setiap peserta dan kegiatan praktek dengan mengoperasikan aplikasi Geogebra dan Maplesoft serta menyelesaikan soal-soal matematika dengan mengggunakan aplikasi tersebut.
\end{abstract}

Kata kunci : Teknologi Komputer, Media Pembelajaran

\section{ABSTRACT}

In Tlanakan Pamekasan, there are plenty of MTS teachers used only manual media in their teaching and learning activities. One of th reason is their less of knowledge in operating computer for creating computer based media. The solution for this problem can be in form of teacher training by using application or computer programme as a teaching and learning media. That applicafion can be a geogebra Or maple software which can be applied by the teachers. This software is applied as teaching and learning media in most of public schools. The target is developing teachers understanding in using teaching media especially in mathematics technology based media. Further it also develops teachers' skill in using geogebra and maple for virtual mathematics media. The respond of this dedication activity is positive showed from mathematics teachers of junior high school /MTS because it helped teachers and also this activity gave kinds of module and practicing geogebra and maplesoft application to each teachers. Further, this activity also help the teacher in solving mathemafics exercises by using those application.

Keywords : Computer application, learning media.

\section{(1) PENDAHULUAN}

Dalam pembelajaran matematika siswa diharapkan mampu menguasai konsepkonsep, teori serta prinsip-prinsip penerapannya. Konsep tersebut menjadi dasar yang harus diberikan secara benar dan ditansferkan pada siswa. Proses transfer inilah yang menjadi kunci keberhasilan guru mampu mengajarkan konsep matematika sehingga mudah dipahami oleh siswa. Keberhasilan proses belajar mengajar matematika tidak terlepas dari persiapan siswa dan persiapan guru. Siswa yang siap belajar matematika akan merasa senang dan dengan penuh perhatian mengikuti pembelajaran tersebut. Oleh karena itu, setiap guru perlu memahami secara baik 
Dipublikasikan: Desember 2017

peran dan fungsi strategi dalam pelaksanaan proses pembelajaran (Zayyadi, 2014).

Salah satu strategi yang digunakan dnegan media pembelajaran, dengan penggunaan media pembelajaran diharapkan mampu dapat mempermudah siswa untuk menerima konsep matematika yang memang abstrak adanya. Media pembelajaran disini dapat berupa media manual ataupun berbasis IT (media virtual). Dengan adanya kemajuan teknologi yang berkembang pesat saat ini, sangat diharapkan dapat dimanfaatkan oleh kalangan pendidik untuk menunjang proses pembelajaran. Pemanfaatan teknologi informasi dan komunikasi untuk pendidikan dapat dilaksanakan dalam berbagai bentuk sesuai dengan fungsinya dalam pendidikan. Berbagai aplikasi teknologi informasi dan komunikasi sudah tersedia untuk masyarakat dan sudah siap menanti untuk dimanfaatkan secara optimal untuk keperluan pendidikan.

Di daerah Tlanakan Pamekasan banyak para guru MTs yang hanya menggunakan media secara manual saja dalam pembelajaran yang dilakukannya. Ada beberapa alasan yang diungkapkan oleh beberapa guru matematika dari beberapa sekolah yang telah kami survei mengenai minimnya pemanfaatan teknologi dalam proses pembelajaran. Diantaranya, kurangnya pengetahuan mereka dalam penggunaan aplikasi komputer untuk menciptakan suatu media yang berbasis teknologi. Berdasarkan analisis situasi dan tinjauan dari berbagai sumber informasi yang berkaitan dengan sistem pembelajaran maka dapat disimpulkan bahwa guru-guru matematika khususnya guru MTs di daerah Tlanakan Pamekasan masih memerlukan pelatihan tentang media pembelajaran dengan pemanfaatan teknologi yang dapat memudahkan siswa dalam memahami konsep matematika yang bersifat abstrak sehingga dapat dikonkretkan.

Latuheru (1988) menyatakan bahwa media pembelajaran adalah bahan, alat atau teknik yang digunakan dalam kegiatan belajar mengajar dengan maksud agar proses interaksi komunikasi edukasi antara guru dan siswa dapat berlangsung secara tepat guna dan berdayaguna. Sudjana, dkk. (2002:2) menyatakan tentang tujuan pemanfaatan media adalah (1) pengajaran akan lebih menarik perhatian siswa sehingga dapat menimbulkan motivasi, (2) bahan pelajaran akan lebih jelas maknanya sehingga dapat lebih dipahami, (3) metode mengajar akan lebih bervariasi, dan (4) siswa akan lebih banyak melakukan kegiatan belajar. Dari beberapa pengertian di atas, media pembelajaran adalah bahan, alat atau teknik yang digunakan dalam kegiatan belajar mengajar dan membantu siswa dalam memahami masalah-masalah abstrak untuk dikonkretkan.

Oleh karena itu, pelatihan ini meliputi pemberian aplikasi-aplikasi komputer yang nantinya diperlukan dalam kegiatan pembelajaran dan bisa diterapkan di sekolah. Aplikasi yang baik adalah aplikasi yang dapat memvisualisasikan materi yang abstrak, yang banyak ditemukan dalam materi-materi dalam pelajaran matematika.

\section{(2) METODE}

Beberapa alternatif yang mungkin dilakukan untuk memecahkan di latar belakang dan permasalahan diantaranya adalah :

1. Memberikan pelatihan tentang media pembelajaran yang seharusnya dilakukan oleh MGMP Mata Pelajaran Matematika untuk lembaga SMP/MTs Kecamatan Tlanakan.

2. Memberikan pelatihan tentang Teknologi computer berupa Geogebra dan Maple kepada guru-guru mata pelajaran matematika SMP/MTs Kecamatan Tlanakan

Berdasarkan analisis situasi dan pemaparan salah satu guru di salah satu lembaga MTs bahwa kerangka pemecahan masalah yang pertama belum 
Dipublikasikan: Desember 2017

direalisasikan dan hanya sebatas wacana dan wacana. Oleh karena itu kami tim pengabdian mengambil langkah solutif dengan memberikan pemecahan masalah

dengan menggunakan kerangka yang kedua karena bukan hanya wacana saja tetapi dapat dilaksanakan dan tidak perlu menunggu dari MGMP tersebut.

Skema di bawah ini merupakan alur tahapan kerja yang akan dilakukan dalam kegiatan ini:

Diagram : skema alur kegiatan

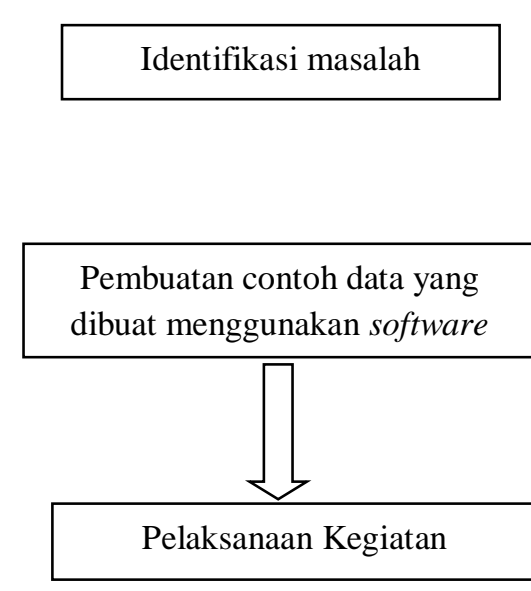

Pelaksanaan tentang realisasi pemecahan masalah dapat dilihat pada table berikut ini

Tabel 1: Kegiatan Ipteks bagi Masyarakat

\begin{tabular}{|c|c|c|}
\hline Program & Kegiatan & $\begin{array}{c}\text { Realisasi } \\
\text { Kegiatan }\end{array}$ \\
\hline $\begin{array}{l}\text { Pelatihan } \\
\text { tentang } \\
\text { media } \\
\text { aplikasi } \\
\text { computer }\end{array}$ & $\begin{array}{l}\text { - Pemberian } \\
\text { modul dan } \\
\text { software } \\
\text { Geogebra } \\
\text { dan } \\
\text { Maplesoft } \\
\text { - Pelatihan } \\
\text { pengunaan } \\
\text { aplikasi } \\
\text { geogebra } \\
\text { - Pelatihan } \\
\text { pengunaan } \\
\text { aplikasi } \\
\text { Maple }\end{array}$ & $\begin{array}{l}100 \% \\
\text { dilaksanakan } \\
\text { pada hari } \\
\text { pertama } \\
\text { tentang } \\
\text { geogebra dan } \\
\text { hari kedua } \\
\text { tentang maple }\end{array}$ \\
\hline
\end{tabular}

(sumber: Data peneliti, 2016)

Kegiatan pengabdian kepada masyarakat ini dimulai dengan mengidentifikasi masalah yang ada di masyarakan khususnya para guru matematika di daerah Tlanakan yang selama ini masih belum paham tentang aplikasi komputer sebagai salah satu saran media pembelajaran, kemudian langkah berikutnya berbagai metode dalam pembelajaran matematika coba diberikan.

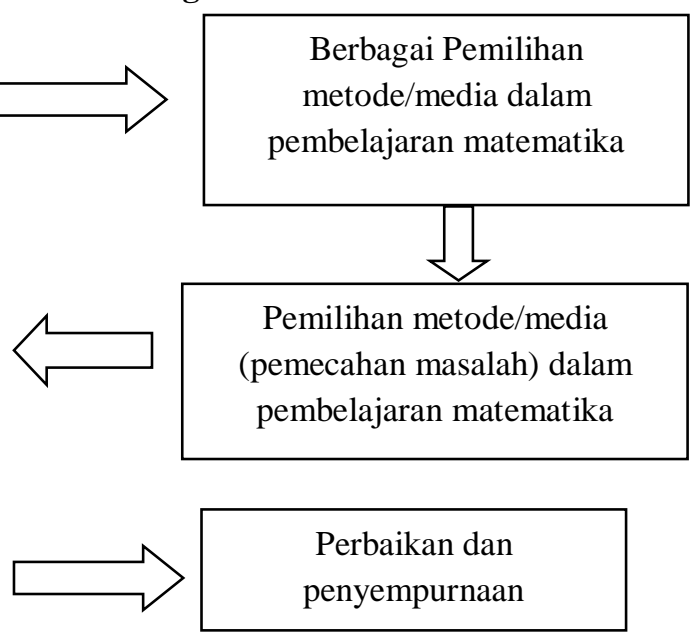

Mereka masih hanya berpatokan pada media yang bersifat manual. Dengan adanya aplikasi komputer berupa Maple dan Geogebra kami sebagai pelaksana kegiatan akan menggunakan software tersebut untuk mengembangkan kemampuan mereka dalam bidang media pembelajaran matematika. Sehingga mereka berpikir tidak hanya dengan media manual, juga media komputer (software) dapat digunakan sebagai media pembelajaran matematika. Selanjutnya pada keagiatan pelaksanaan akan diberikan pelatihan cara mengoperasikan software sebagai media pembelajaran. Dalam kegiatan ini akan diberikan umpan balik terhadap kegiatan yang dilakukan sebagai evaluasi. Langkah terakhir kegiatan akan melakukan evaluasi dan penyempurnaan terhadap hasil yang diperoleh pada saat kegiatan berlangsung.

Pelaksanaan tentang realisasi pemecahan dilaksanakan selama 2 hari di Laboratorium Micro Teaching FKIP Universitas Madura dengan materi hari 
Dipublikasikan: Desember 2017

pertama tentang Geogebra dan hari kedua tentang maple. Peserta kegiatan pengabdian pada masyarakat ini adalah guru-guru mata pelajaran matematika di lingkup kecamatan Tlanakan. Tim pelaksana mengundang peserta dari tingkat Sekolah Menengah Pertama dan ada pula dari tingkatan Madrasah Tsanawiyah.

\section{(3) PEMBAHASAN DAN HASIL}

Dengan penggunaan media pembelajaran dalam proses kegiatan belajar mengajar mempermudah pemahaman materi-materi yang membutuhkan sesuatu yang konkrit dan dapat langsung dipahami oleh siswa. Media pembelajaran dalam matematika bisa berupa alat peraga/model, lembar kegiatan siswa, tayangan, software, dan sebagainya. Media pembelajaran tidak selalu berbentuk alat peraga. Papan tulis bisa menjadi media pembelajaran utama untuk menjelaskan beberapa pokok bahasan.

Media pembelajaran adalah bahan, alat atau teknik yang digunakan dalam kegiatan belajar mengajar dan membantu siswa dalam memahami masalah-masalah abstrak untuk dikonkretkan. Teknologi informasi dan komunikasi juga sangat bermanfaat dalam bidang pendidikan, salah satunya adalah media pembelajaran teknologi komputer. Sasaran penggunaan media adalah agar anak didik mampu menciptakan sesuatu yang baru dan mampu memanfaatkan sesuatu yang telah ada untuk dipergunakan dengan bentuk dan variasi lain yang berguna dalam kehidupannya.

Aplikasi tersebut berupa software geogebra dan maple yang nantinya bisa diterapkan oleh para guru. software seperti ini sudah banyak diaplikasikan sebagai alat pembelajaran di berbagai sekolah negeri. Geogebra dalah program komputer (software) untuk membelajarkan matematika khsusunya geometri dan aljabar. Software Geogebra menjadi pilihan peneliti karena melihat karakteristik siswa-siswa MTs yang masih menyukai konsep permainan. Software Geogebra berfungsi sebagai media gambar yang dinamis sehingga siswa akan bermain dengan geseran titik-titik ataupun pengukuran ruas garis dan luasan. Secara umum software Geogebra akan menyediakan pengalaman langsung kepada siswa dalam belajar. Dengan demikian, software Geogebra mendukung kegiatan pembelajaran dan dapat memotivasi siswa dalam belajar.

Berikut salah satu penggunaan geogebra dalam pembelajaran matematika seperti pada gambar 1 .

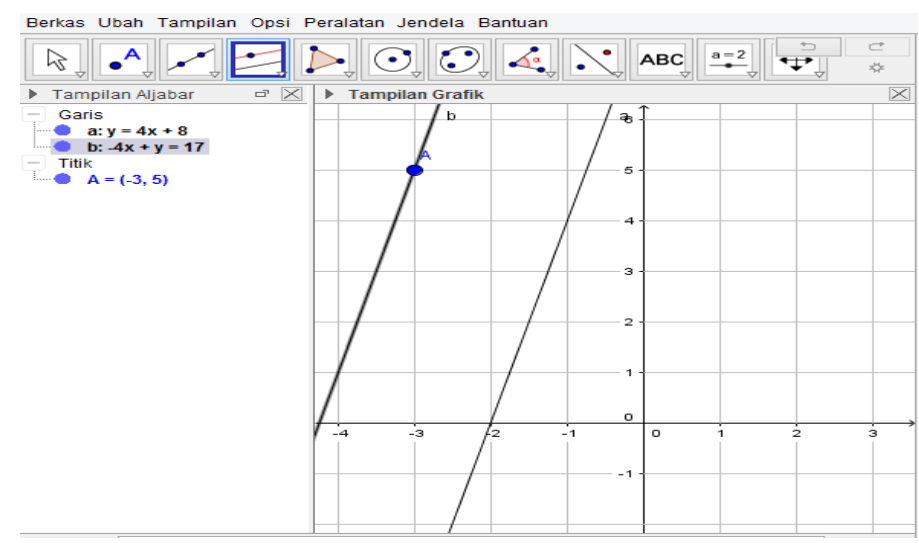

Gambar 1 : Salah satu penggunaan Geogebra dalam Pembelajaran Matematika

Maple adalah program yang biasa digunakan pada bidang matematika, dan bidang eksak lainnya. Maple dapat dioperasikan menggunakan $O S$ Windows 
dan cuku mudah dalam penggunaanya. Penggunaan maple dapat menjadi sebuah solusi alternatif untuk digunakan dalam penyajian materi pembelajaran matematika. Maple dapat membantu menyelesaikan masalah kalkulus dasar (limit, diferensial, integral), kalkulus

\section{(Halaman 25-30)}

lanjutan, aljabar linier, program linier, fungsi kuadrat, pemodelan matematika dan masih banyak lagi.

Berikut salah satu penggunaan Maple dalam pembelajaran matematika seperti pada gambar 2.

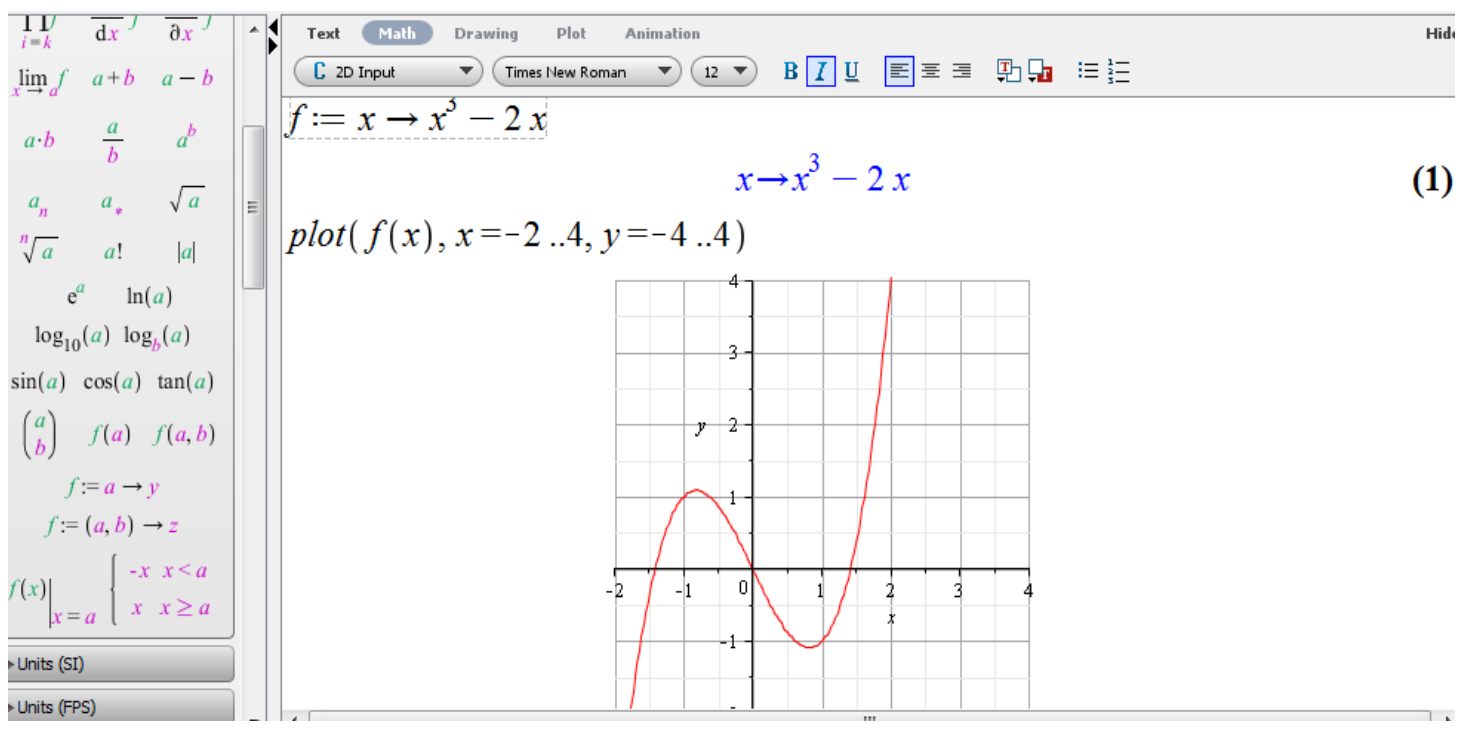

Gambar 2. Salah satu penggunaan Maple dalam Pembelajaran Matematika.

\section{Hasil}

Dari hasil temuan di atas dapat disimpulkan bahwa selama proses pengabdian ini sangat membantu para guru khususnya guru matematika di kecamatan Tlanakan. Hal ini terlihat dari respon peserta setelah mengikuti pelatihan ini. Dari beberapa item yang ada dalam lembar angket dan kolom komentar semua peserta menyatakan sangat terbantu dengan adanya pelatihan ini, selain menambah wawasan dan pengetahuan juga dapat mempermudah dalam mengerjakan soal-soal matematika serta dapat diterapkan dalam kegiatan belajar mengajar. Pemberian modul dan aplikasi juga membantu peserta dalam mengoperasikan langkah-langkah aplikasi tersebut karena dalam pengabdian ini tidak hanya praktek saja tetapi juga teori disampaikan.

Hal ini sejalan dengan pendapat (Ruseffendi, 1988) yang menyatakan dapat mendorong guru untuk meningkatkan pengetahuan dan kemampuan mengenai komputer. Penggunaan komputer dalam pembelajaran matematika banyak peranannya, baik sebagai alat hitung maupun sebagai alat penyampaian materi pelajaran. Sebagai alat hitung, komputer dapat melakukan perhitungan untuk mencari: logaritma, perbandingan trigonometri, operasi hitung, dan sebagainya. Sedangkan sebagai alat/media penyampaian materi pelajaran, komputer dapat diprogram untuk membantu siswa dalam belajar (pembelajaran individu). Dalam pembelajaran matematika, komputer banyak digunakan untuk menyampaikan materi yang memerlukan gerak (animasi), gambar, teks, dan warna. Semua fasilitas tersebut ada pada komputer dan semua fasilitas tersebut dapat dimanfaatkan untuk memvisualisasikan konsep abstrak dalam matematika menjadi konkret. Akan tetapi Meskipun penggunaan komputer dapat meningkatkan prestasi siswa, komputer tidak dapat mengganti peran guru secara keseluruhan (NCTM, 2000:26). 


\section{(4) PENUTUP}

Berdasarkan hasil dan pembahasan diatas dapat disimpulkan bahwa:

1. Kegiatan pengabdian mendapatkan respon positif dari guru-guru matematika SMP/MTs dikarenakan dapat membantu guru-guru dalam mengerjakan soal matematika. Selain itu, dapat menambah wawasan dan pengetahuan juga dapat mempermudah dalam mengerjakan soal-soal matematika serta dapat diterapkan dalam kegiatan belajar mengajar. Pemberian modul dan aplikasi juga membantu peserta dalam mengoperasikan langkah-langkah aplikasi tersebut karena dalam pengabdian ini tidak hanya praktek saja tetapi juga teori disampaikan. Hal ini dapat dilihat dari hasil analisis respon yang secara garis besar guru-guru menyatakan "iya" merasa terbantu dengan pelatihan ini.

\section{(5) DAFTAR PUSTAKA}

Latuheru, D. J. (1988). Media Pembelajaran dan Proses Hasil Belajar Mengajar Masa Kini. Jakarta: Depdikbud Dikti P2LPTK.

NCTM. (2000). Principles and Standards for School Mathematics. Virginia: The NCTM, Inc.

Ruseffendi. (1988). Pengajaran Matematika Modern dan Masa Kini
2. Kegiatan pengabdian ini berbentuk teori dengan memberikan modul pada setiap peserta dan kegiatan praktek dengan mengoperasikan aplikasi Geogebra dan Maplesoft serta menyelesaikan soal-soal matematika dengan mengggunakan aplikasi tersebut.

3. Berdasarkan hasil temuan di atas, tim memberikan saran sebagai berikut: Adanya tindak lanjut dan evaluasi terhadap peserta dalam menggunakan modul dan aplikasi yang diberikan oleh Tim pengabdian untuk diaplikasikan dalam kegiatan belajar mengajar dan Perlunya perluasan kegiatan pengabdian yang tidak hanya dalam lingkup kecamatan saja tetapi juga dalam lingkup kabupaten sehingga guru-guru lebih melek teknologi dan tidak terlalu gaptek dalam teknologi yang semakin canggih.

untuk Guru dan SPG, Seri Kedua. Bandung: Tarsito.

Sudjana, N dan Rivai, A. (2002). Media Pengajaran. Bandung: Sinar Baru Algesindo.

Zayyadi, (2014). Pengaruh Strategi Pembelajaran Peningkatan Kemampuan Berpikir terhadap Hasil Belajar. Interaksi Kependidikan. 9 (1). 